\title{
Arahan Pengembangan "Kampung Majapahit" sebagai Desa Wisata pada Kawasan Cagar Budaya Kecamatan Trowulan, Kabupaten Mojokerto
}

\author{
Jovany Aliflyantera Adistana dan Haryo Sulistyarso \\ Jurusan Perencanaan Wilayah dan Kota, Fakultas Teknik Sipil dan Perencanaan, Institut Teknologi \\ Sepuluh Nopember (ITS) \\ Jl. Arief Rahman Hakim, Surabaya 60111 Indonesia \\ e-mail: haryo.its@gmail.com
}

\begin{abstract}
Abstrak-Kampung Majapahit merupakan kawasan kampung wisata yang terdiri dari 3 desa yaitu Desa Bejijong, Sentonorejo, dan Jatipasar. Pada kampung wisata ini terdapat banyak potensi wisata situs Trowulan dan juga potensi ekonomi kreatif di dalamnya. Di dalam ketiga desa tersebut banyak pengerajin seperti patung, batik, cor kuningan dan tembaga. Dalam potensi di atas terdapat permasalahan yang dimiliki Kampung Majapahit ini terutama pada integrasi antar kampung. Integrasi di sini adalah sebagai fungsi dan peran masing masing desa belum sepenuhnya terlihat. Sehingga dalam pengembangannya, pengembangan banyak terlihat pada Desa Bejijong. Penelitian ini memiliki 3 tahap analisa. Tahap pertama yaitu mengidentifikasi potensi pada Kampung Majapahit pada kawasan deliniasi yang dapat dikembangkan sebagai kawasan wisata dengan menggunakan analisis theoritical descriptive. Tahap kedua adalah menganalisis faktor penenentu pengembangan Kampung Majapahit sebagai desa wisata budaya. Dalam tahap ketiga ini digunakan analisis analisis zona dan analisa theoritical descriptive. Hasil penelitian menunjukan bahwa Kampung Majapahit memiliki potensi yang dapat dikembangkan menjadi salah satu destinasi wisata budaya. Arahan pengembangan dan pengintegrasian kawasan ditunjang dengan analisa zona dan faktor pendukung pengembangan Kampung Majapahit. Sementara output dalam analisa zonasi Kampung Majapahit dibagi menjadi 2, yakni arahan makro dan mikro. Arahan pengembangan kawasan sebagai wisata budaya Kampung Majapahit secara mikro adalah pembagian zona pengembangan kegiatan wisata menjadi 3 zona, antara lain zona inti, zona pendukung langsung, dan zona pendukung tidak langsung. Hasil analisis zonasi tersebut pusat pengembangan Kampung Majapahit dipusatkan pada Desa Bejijong yang memiliki kepadatan bangunan dan rumah Majapahit yang tinggi. Sementara Desa Jatipasar dan Desa Sentonorejo diarahkan untuk desa penyangga yang menunjang sarana dan prasarana pariwisata Kampung Majapahit. Sementara arahan pengembangan makro merupakan arahan umum untuk ketiga zona pengembangan kegiatan wisata Kampung Majapahit.
\end{abstract}

Kata Kunci-Kawasan Cagar Budaya, Pengembangan Kampung Wisata Budaya, Pengintegrasian Wisata Budaya

\section{PENDAHULUAN}

$\mathrm{K}$ AWASAN cagar budaya, perkotaan atau dikenal juga dengan urban heritage merupakan sebuah kawasan yang pernah menjadi pusat-pusat dari sebuah kompleksitas fungsi dari kegiatan ekonomi, sosial, budaya yang memiliki latar belakang makna sejarah (historical significance).

Kawasan cagar budaya pada dasarnya memiliki kekayaan tipologi dan morfologi urban heritage yang berupa situs historis, kawasan historis dan histori budaya. Pengembangan kawasan cagar budaya erat kaitannya dengan keberadaan situs. Khususnya pada wilayah lindung, kedua aspek di atas memiliki implikasi besar pada keberlangsungan ekologi dan ekonomi komunitas di dalam dan sekitarnya.

Kawasan cagar budaya yang terdapat di Kabupaten Mojokerto adalah kawasan cagar budaya Majapahit. Bedasarkan keputusan Menteri Pendidikan nomor 260/M/2013, Kecamatan Trowulan, Kabupaten Mojokerto merupakan wilyah dengan situs cagar budaya dan telah diakui secara nasional sebagai kawasan strategis cagar budaya nasional. Kebudayaan obyek-obyeknya sebagian besar merupakan situs peninggalan era Majapahit. Situs yang banyak ditemukan di kawasan ini merupakan situs situs komplek candi yang terdiri dari Candi Brahu, Bajang Ratu, Gentong, Tikus dan Kolam Segaran. Kebanyakan situs peninggalan yang lain masih dalam proses identifikasi dan penyelamatan, meski ada pula yang telah dipugar dan dipamerkan. Mahapahit mewarisi pola dasar tata ruang universal, yang dikembangkan sejak awal perkembangan kota, pada sekitar tiga milenium sebelum Masehi. Gubahan ruang khas Majapahit terdiri atas gabungan antara pola ruang berpusat pada kawasan inti yang berpola papan catur atau grid dengan pola organis atau sirkular melingkar pada kawasan luar, yang berkembang dari arah pusat ke tepi kawasan [1].

Berdasarkan Rencana Induk Pembangunan Pariwisata Daerah RIPPDA Kabupaten Mojokerto tahun 2007 tentang wisata budaya dan peninggalan sejarah, dimana terdapat situs bersejarah yang memiliki nilai kultural yang tinggi yang lokasinya terdapat di Kecamatan Trowulan, yaitu situs bekas kerajaan Majapahit (cagar budaya) yang dikembangkan menjadi Mojopahit Park. Mojopahit Park merupakan komplek situs sejarah Kerajaan Mojopahit yang terdiri atas beberapa peninggalan sejarah berupa candi, museum Mojopahit, dan juga Kampung Majapahit. Kampung Majapahit sendiri merupakan sebuah rencana kampung tematik yang memiliki ciri desain arsitektural zaman Majapahit. Lebih lanjut Kampung Majapahit juga merupakan kawasan penunjang pariwisata bagi situs situs Majapahit di Kecamatan Trowulan [2].

Kampung Majapahit merupakan kawasan yang terdiri dari 3 
desa yang memiliki potensi wisata situs Trowulan dan juga potensi ekonomi kreatif didalamnya. Di dalam ketiga desa tersebut banyak pengerajin seperti patung, batik, cor kuningan dan tembaga. Potensi tersebut merupakan atraksi yang khas pada 3 desa yang terdeliniasi Kampung Majapahit. Salah satunya adalah Desa Bejijong yang merupakan core bagi pengembangan Kampung Majapahit. Hal ini dikarenakan potensi situs Majapahit yang dimiliki Desa Bejijong merupakan yang paling banyak dari desa yang lain. Situs dalam Desa Bejijong antara lain Situs Candi Brahu, Makam Siti Inggil (Makam Raden Wjaya) serta Vihara Majapahit (Patung Budha), Selain itu potensi yang ada pada Desa Bejijong yaitu potensi kerajinan Patung, Batik, Cor Kuningan dan Tembaga [3].

Dalam potensi potensi di atas terdapat permasalahan yang dimiliki tersebut mengerucut dalam hal pengembangan Kampung Majapahit ini terutama pada integrasi antar kampung. Dalam hal ini integrasi sebagai fungsi dan peran masing masing desa belum sepenuhnya terlihat. Sehingga dalam pengembangannya, pengebangan banyak terlihat pada Desa Bejijong. Disisi lain, menurut survei lapangan pengembangan Kampung Majapahit Desa Bejijong sudah mencapai 60\%, namun pengembangan ini tidak didukung dengan adanya pengembangan rumah dan fasilitas pendukung di kampung yang lain, sehingga dalam implementasinya kurang selaras dan masih menimpang pada Desa Bejijong. Di sisi lain Desa Sentonorejo dan Desa Jatipasar yang menjadi deliniasi kawasan Kampung Majapahit memiliki potensi yang sama dengan Desa Bejijong. Potensi tersebut adalah potensi kerajinan kreatif seperti batik, pemahat patung dan industri batu bata [4].

Perkembangan sebuah kawasan yang berkembang menuntut pengelolaan fungsi kawasan yang lebih baik karena semakin berkembang suatu kawasan maka unsur-unsur pembentuknya pun akan semakin kompleks pula. Pada pengembangan Kampung Majapahit belum sepenuhnya memiliki integrasi mengenai fungsi dan peran antar desa, sehingga dalam hal ini penunjang situs cagar budaya pada Kecamatan Trowulan hanya berpusat pada satu desa yaitu Desa Bejjijong. Sehingga dalam pengembangan wilayah Desa Bejijong yang menjadi pusat Kampung Majapahit terus berkembang dan tidak dibarengi dengan pemerataan pada desa yang terdeliniasi Kampung Majapahit. Sehingga pemerataan dalam pengembangan desa wisata pada kawasan perlu untuk di tinjau sehingga terdapat pengintegrasian antar kampung wisata. [5]

Oleh karena itu dalam pemecahan masalah masalah di atas perlu adanya arahan pengembangan dan pengintegrasian antar kampung sebagai desa wisata Kampung Majapahit. Sehingga dalam prakteknya pengembangan Kampung Majapahit dapat terintegrasi dan mengikuti pola yang sudah ditentukan guna mendukung pengembangangan pariwisata Majapahit. Dengan dilakukannya penelitian terhadap arahan pengembangan desa wisata Kampung Majapahit diharapkan dapat diperoleh arahan baru dalam melakukan mekanisme pengembangan ke depan.

Pada akhirnya penelitian ini juga diharapkan dapat bermanfaat bagi kemajuan dan pengembangan Kampung Majapahit, Kecamatan Trowulan Kabupaten Mojokerto [6].

\section{METODE PENELITIAN}

\section{A. Jenis dan Pendekatan Penelitian}

Pendekatan yang digunakan dalam penelitian ini adalah pendekatan rasionalistik [7]. Jenis penelitian dalam penelitian ini adalah deskripti kuantitatif.

\section{B. Variabel Penelitian}

Berdasarkan kajian literatur yang telah dilakukan, didapatkan beberapa variabel yang mendukung dalam penelitian ini guna mencapai sasaran dalam penelitian. Variabel yang digunakan dalam penelitian ini merupakan hasil dari sintesa teori pada bab kajian pustaka yang dalam hal ini sintesa teori sudah selaras dengan ruang lingkup penelitian. Dalam penelitian ini variabel yang digunakan untuk mengetahui potensi pada Kampung Majapahit adalah nilai sejarah kawasan cagar budaya, memiliki pengaruh dengan lingkungan sekitarnya, kepadatan cagar budaya, potensi ekonomi, sebaran infrastruktur.

Sementara itu variabel penelitian yang faktor pengembangan Kampung Majapahit antara lain mata pencaharian penduduk, potensi desa, tingkat pendidikan, tingkat kecukupan sarana pendidikan, kondisi perumahan, tingkat ketersediaan sarana perdagangan, tingkat ketersediaan prasarana listrik, dan tingkat ketersediaan prasarana air bersih.

\section{Identifikasi Potensi Desa Wisata Budaya Kampung Majapahit}

Dalam ketercapaian sasaran ini, digunakan teknik analisis deskriptif dengan metode theoritical descriptive dan empirical descriptive. Metode ini digunakan untuk menggambarkan potensi desa yang diteliti secara sistematis, faktual, dan akurat. Proses analisis theoritical descriptive merupakan proses analisis data secara kualitatif dengan menggunakan data yang diperoleh dari data sekunder yang dijelaskan secara deskriptif dan normatif yang disesuaikan dengan kondisi existing obyek penelitian yaitu pada peruntukan Kampung Majapahit Kabupaten Mojokerto. Sedangkan analisis Empirical Descriptive merupakan proses analisis dengan mengidentifikasi data primer yang dikolaborasikan. Data primer tersebut berupa karakteristik individu/obyek, kelompok, dan komunitas. Dari kedua analisis tersebut akan didapatkan kesesuaian variabel antara data primer dan data sekunder.

\section{Menganalisis Faktor Penentu Pengembangan Kampung Majapahit Sebagai Desa Wisata}

Pada tahap ini dilakukan analisis terhadap faktor penentu kelayakan pengembangan kawasan desa wisata yang dihasilkan dari wawancara pada responden terkait telah mencapai konsensus. Bila dalam proses wawancara data yang dianalisa belum mencapai konsensus, akan dilakukan iterasi hingga dihasilkan faktor-faktor yang konsensus antar responden terkait. Hasil dari analisis delphi adalah kelayakan pengembangan kawasan penelitian sebagai kawasan desa wisata. Dalam analisis delphi, ada beberapa tahap yang dilakukan yaitu:

1. Wawancara Responden

Wawancara stakeholder bertujuan untuk mengetahui variabel yang dirumuskan dari hasil kajian pustaka. Sedangkan stakeholder yang diwawancara adalah stakeholder yang telah 
ditentukan dalam sampel penelitian. Wawancara dilakukan untuk mengisi kuesioner sehingga diketahui faktor penyebab penurunan vitalitas kawasan cagar budaya.

2. Tampilan Data Hasil Wawancara

Dari hasil ringkasan wawancara dan proses reduksi, selanjutnya diperoleh kesimpulan mengenai penetapan dan pengembangan desa wisata. Hasil wawancara pertama akan dijadikan masukan bagi tahap selanjutnya, yaitu melalui proses iterasi.

3. Iterasi dan Penarikan Kesimpulan

Iterasi ditunjukan untuk memastikan apakah instrumen hasil wawancara sesuai dengan maksud yang diberikan oleh masing-masing stakeholder. Dari hasil identifikasi instrument berdasarkan opini tiap-tiap responden tersebut kemudian disederhanakan atau dikelompokkan secara substansial.

E. Perumusan Arahan Pengembangan Desa Tertinggal Kabupaten Bondowoso Berdasarkan Aspek-Aspek yang diprioritaskan menggunakan Analisis Deskripti Narasi

Dalam penentuan arahan pengembangan desa tertinggal Kabupaten Bondowoso berdasarkan aspek-aspek yang diprioritakan menggunakan analisis deskriptif berbentuk narasi. Dalam melakukan metode analisis ini dilakukan dengan cara membandingkan antara hasil analisis topologi desa tertinggal dengan kondisi existing.

\section{HASIL DAN DISKUSI}

A. Menganalisis Faktor Penentu Pengembangan Kampung Majapahit Sebagai Desa Wisata

Untuk mendapatkan faktor penentu pengembangan Kampung Majapahit ke depan menggunakanteknik analisis delphi. Analisis delphi merupakan suatu usaha untuk memperoleh consensus group yang dilakukan secara kontinu, sehingga didapatkan kesamaan opini dari setiap responden. Selanjutnya, responden yang telah dipilih berperan untuk menentukan faktor yang berpengaruh pada pengembangan Kampung Majapahit ke depan responden analisis delphi dalam penelitian ini dapat dilihat pada tabel berikut.

Tabel 1

Responden penelitian

\begin{tabular}{ll}
\hline \hline \multicolumn{1}{c}{ Nama Responden } & \multicolumn{1}{c}{ Pekerjaan } \\
\hline Kuswanto & $\begin{array}{l}\text { Koordinator Pokja BP3 Trowulan } \\
\text { Kepala Bidang Fisik dan Prasarana } \\
\text { Dian Indrianingrum S.T.,M.T. }\end{array}$ \\
$\begin{array}{l}\text { Bappeda Kabupaten Mojokerto } \\
\text { Kepala Bidang Perencanaan dan Tata } \\
\text { Ruang Bappeprov Jatim }\end{array}$ \\
Kasi Bidang Cagar Budaya Dinas \\
I Gede Ariawan & $\begin{array}{l}\text { Pariwisata Prov. Jatim } \\
\text { Staff Bidang Tata Ruang Dinas Ciptakarya } \\
\text { dan Tataruang Prov Jawatimur }\end{array}$ \\
M. Alfarizi &
\end{tabular}

Sumber: Penulis, 2016

Dari beberapa variabel yang didapat dari tinjauan pustaka kemudian dianalisis sesuai dengan kondisi existing yang dibandingkan dengan literatur untuk memperoleh faktor. Disimpulkan bahwa faktor yang dapat mempengaruhi pengembangan Kampung Majapahit yang didapatkan dari hasil perbandingan antara variabel, teori, dan kondisi existing. Faktor-faktor pengembangan Kampung Majapahit antara lain:

1. Adanya nilai sejarah pada Kampung Majapahit yang didapat dari banyaknya bangunan atau peninggalan situs Majapahit.

2. Adanya pengaruh eksternal yang dapat menjadi pengaruh dalam pengembangan Kampung Majapahit

3. Kampung Majapahit memiliki ciri khas budaya sehingga dapat dijual sebagai daya tari wisata pada Kampung Majapahit

4. Tersedianya sarana dan prasarana dasar pariwisata pada Kampung Majapahit

5. Tersedianya fasilitas pendukung pariwisata namun perlu adanya penambahan fasilitas pendukung pariwisata

6. Fasilitas pelayanan desa wisata

7. Kemudahan aksesibitas pada Kampung Majapait Kualitas sarana dan prasarana jaringan jalan menuju Kampung Majapahit

- Eksplorasi Analisis Delphi Tahap I

Untuk melakukan eksplorasi pendapat responden, peneliti menggunakan kuesioner wawancara untuk membantu peneliti dalam proses wawancara. Penggunaan kuesioner wawancara tersebut memungkinkan responden untuk dapat mengungkapkan pendapatnya secara langsung dan lebih mendalam. Hal tersebut membantu peneliti dalam menentukan pendapat responden terhadap faktor yang mempengaruhi pengembangan Kampung Majapahit.

Tabel 2

Eksplorasi delphi tahap 1

\begin{tabular}{|c|c|c|c|c|c|c|}
\hline \multirow{2}{*}{ No } & \multirow{2}{*}{ Faktor } & \multicolumn{5}{|c|}{ Responden } \\
\hline & & R1 & R2 & R3 & R4 & R5 \\
\hline 1 & $\begin{array}{l}\text { Adanaya nilai sejarah pada Kampung } \\
\text { Majapahit yang didapat dari } \\
\text { banyaknya bangunan atau peninggalan } \\
\text { situs Majapahit. }\end{array}$ & $S$ & $S$ & $S$ & S & $\mathrm{S}$ \\
\hline 2 & $\begin{array}{l}\text { Adanya ciri khas budaya sehingga } \\
\text { dapat dijual sebagai daya tari wisata } \\
\text { pada Kampung Majapahit }\end{array}$ & $S$ & $S$ & $S$ & S & $S$ \\
\hline 3 & $\begin{array}{l}\text { Adanya pengaruh eksternal yang dapat } \\
\text { menjadi pengaruh dalam } \\
\text { pengembangan Kampung Majapahit }\end{array}$ & $S$ & TS & $S$ & TS & $\mathrm{S}$ \\
\hline 4 & $\begin{array}{l}\text { Memiliki sarana dan prasarana yang } \\
\text { mendukung seperti listrik, jaringan } \\
\text { telekomunikasi dll }\end{array}$ & $S$ & S & $S$ & $S$ & $S$ \\
\hline 5 & $\begin{array}{l}\text { Ketersediaan fasilitas pelayanan desa } \\
\text { wisata seperti museum, information } \\
\text { centre, dll }\end{array}$ & S & $\mathrm{S}$ & S & $\mathrm{S}$ & $S$ \\
\hline 6 & $\begin{array}{l}\text { Ketersediaaan fasilitas pelayanan desa } \\
\text { wisata seperti gallery seni pusat oleh } \\
\text { oleh, faslitas kesehatan dll }\end{array}$ & $S$ & $\mathrm{~S}$ & $S$ & $S$ & $S$ \\
\hline 7 & $\begin{array}{l}\text { Aksesibilitas yang mudah dalam } \\
\text { mengakses Kampung Majapahit }\end{array}$ & $\mathrm{S}$ & $\mathrm{S}$ & $S$ & S & $S$ \\
\hline 8 & $\begin{array}{l}\text { Kualitas sarana dan prasarana jaringan } \\
\text { jalan }\end{array}$ & $S$ & $\mathrm{~S}$ & $S$ & $S$ & $S$ \\
\hline
\end{tabular}

Sumber: Hasil Analisis, 2016 
Hasil eksplorasi delphi menunjukan bahwa faktor pengaruh eksternal merupakan faktor yang belum disetujui oleh para narasumber penelitian. Dalam eksplorasi delphi tahap ini terdapat beberapa faktor tambahan yaitu:

1. Faktor kelembagaan yang saling bersinergi;

2. Ketersediaan investor dalam pegembangan kampung;

3. Adanya dukungan pemerintah;

4. Peran masyarakat pemuda dalam kawasan Kampung Majapahit.

\section{- Iterasi Tahap I Analisis Delphi}

Pada tahap ini selanjutnya dilakukan pengulangan kuesioner setelah didapatkan hasil eksplorasi analisis delphi. Iterasi dibutuhkan dikarenakan terdapat faktor yang belum mencapai konsensus dan penambahan faktor baru pada tahap eksplorasi sebelumnya dijadikan basis dalam peenyusunan kuesioner wawancara di tahap iterasi. Kuesioner wawancara delphi pada tahap iterasi ini pada dasarnya sama dengan kuesioner tahap I. Namun, variabel yang ditanyakan merupakan faktor yang belum mencapai konsensus dan faktor baru. Berikut merupakan hasil iterasi delphi tahap I.

Tabel 3

Hasil iterasi analisa delphi

\begin{tabular}{clcccccc}
\hline \hline \multirow{2}{*}{ No } & \multicolumn{1}{c}{ Faktor } & \multicolumn{1}{c}{ Responden } \\
& \multicolumn{1}{c}{$\begin{array}{l}\text { Adanya pengaruh eksternal yang } \\
\text { dapat menjadi pengaruh dalam } \\
\text { pengembangan Kampung Majapahit }\end{array}$} & S & S & S & S & S \\
2 & $\begin{array}{l}\text { Faktor Kelembagaan yang saling } \\
\text { bersinergi }\end{array}$ & S & S & S & S & S \\
3 & $\begin{array}{l}\text { Ketersediaan investor dalam } \\
\text { pegembangan kampung }\end{array}$ & TS & TS & TS & TS & TS \\
4 & $\begin{array}{l}\text { Adanya dukungan pemerintah } \\
\text { Peran masyarakat pemuda dalam } \\
\text { kawasan Kampung Majapahit }\end{array}$ & $\mathrm{S}$ & $\mathrm{S}$ & $\mathrm{S}$ & $\mathrm{S}$ & $\mathrm{S}$ \\
\hline \hline Sumber: Hasil Analisis, 2016 & & & $\mathrm{S}$ & $\mathrm{S}$ & $\mathrm{S}$ \\
\hline
\end{tabular}

Hasil analisis delphi yang tertera di atas dan telah mencapai konsensus ini merupakan faktor yang mempengaruhi pengembangan Kampung Majapahit ke depan. Pada tahap selanjutnya, faktor-faktor tersebut digunakan untuk merumuskan arahan pengembagan Kampung Majapahit. Berikut merupakan faktor-faktor yang digunakan dalam arahan pengembangan Kampung Majapahit. Berikut faktor yang berpengaruh dalam pengembangan Kampung Majapahit.

Tabel 4

Faktor yang berpangaruh dalam pengembangan Kampung Majapahit

\begin{tabular}{cl}
\hline \hline No & \multicolumn{1}{c}{ Faktor } \\
\hline 1 & $\begin{array}{l}\text { Adanya nilai sejarah pada Kampung Majapahit yang didapat dari } \\
\text { banyaknya bangunan atau peninggalan situs Majapahit. }\end{array}$ \\
2 & $\begin{array}{l}\text { Adanya ciri khas budaya sehingga dapat dijual sebagai daya tarik wisata } \\
\text { pada Kampung Majapahit }\end{array}$ \\
3 & $\begin{array}{l}\text { Adanya pengaruh eksternal yang dapat menjadi pengaruh dalam } \\
\text { pengembangan Kampung Majapahit }\end{array}$ \\
4 & $\begin{array}{l}\text { Memiliki sarana dan prasarana yang mendukung seperti listrik, jaringan } \\
\text { telekomunikasi dll }\end{array}$ \\
5 & $\begin{array}{l}\text { Ketersediaan fasilitas pelayanan desa wisata seperti museum, } \\
\text { information centre, dll }\end{array}$ \\
6 & $\begin{array}{l}\text { Ketersediaaan fasilitas pelayanan desa wisata seperti galeri seni pusat } \\
\text { oleh oleh, fasilitas kesehatan dll }\end{array}$ \\
7 & Aksesibilitas yang mudah dalam mengakses Kampung Majapahit \\
\hline \hline
\end{tabular}

\begin{tabular}{cl}
\hline No & \multicolumn{1}{c}{ Faktor } \\
\hline 8 & Kualitas sarana dan prasarana jaringan jalan \\
9 & Faktor kelembagaan yang saling bersinergi \\
10 & Adanya dukungan dan peran serta masyarakat \\
\hline \hline
\end{tabular}

Sumber: Hasil Analisis, 2016

\section{B. Perumusan Arahan Pengembangan Kampung Majapahit Menjadi Desa Wisata}

Dalam pengembangan kawasan wisata budaya khususnya pada Kampung Majapahit, perlu adannya rumusan zona pengembangan untuk membagi secara jelas fungsi dari masing-masing zona pada kawasan dalam sebuah sistem spasial. Pada pengembangan zona menggunakan pengembangan model Smith menggambarkan hubungan spasial antara kegiatan wisata dengan kegiatan penduduk setempat menjadi 3 zona pengembangan, yaitu:

a) Zona inti, mengandung daya tarik wisata yang menjadikan suatu kawasan sebagai daerah tujuan wisata.

b) Zona pendukung langsung, merupakan pusat dari fasilitas pelayanan yang dibutuhkan oleh masyarakat dan juga wisatawan, seperti pertokoan, jasa pendukung pariwisata, dll.

c) Zona pendukung tidak langsung, merupakan daerah sekitar yang masih terkena dampak dari kawasan wisata secara tidak langsung.

Dalam perumusan arahan pengembangan Kampung Majapahit diambil dari analisa deskriptif dan analisa delphi di atas. Dalam perumusan arahan pengembangan merupakan hasil analisis delphi dan analisis zona pengembangan kegiatan wisata, dihasilkan arahan makro dan mikro kawasan. Arahan ini memiliki lingkup pengaplikasiannya tidak hanya berpengaruh untuk internal Kawasan Kampung Majapahit, tetapi juga memiliki pengaruh untuk pengembangan wisata budaya yang berada di sekitar Kampung Majapahit akan dikelompokkan menjadi arahan makro. Sedangkan arahan yang lingkup pengaplikasiannya hanya berada di dalam Kawasan Kampung Majapahit dan merujuk pada suatu objek atau aspek, akan dikelompokkan menjadi arahan mikro.

Arahan makro pada kampung wisata Budaya Majapahit yang dihasilkan berupa pembatasan zona pengembangan kegiatan wisata. Arahan pengembangan makro merupakan output dari analisis zona pengembangan. Dalam arahan pengembangan Kampung Majapahit untuk seluruh zona pengembangan kegiatan wisata antara lain:

1. Peningkatan kualitas bangunan cagar budaya atau situs candi pada area sekitar Kampung Majapahit;

2. Menjadikan kawasan Kampung Majapahit menjadi kawasan kampung atau desa tematik untuk kegiatan pariwisata budaya

3. Peningkatan sarana pendukung desa wisata. Terutama pada Desa Sentonorejo dan Jatipasar

4. Penambahan sanggar dan sasana pementasan untuk pagelaran seni masyarakat setempat

5. Penataan fasilitas dan street furniture dengan tipologi yang sesuai dengan kerajaan Majapahit

6. Melibatkan masyarakat dalam menjaga maupun mengelola situs 


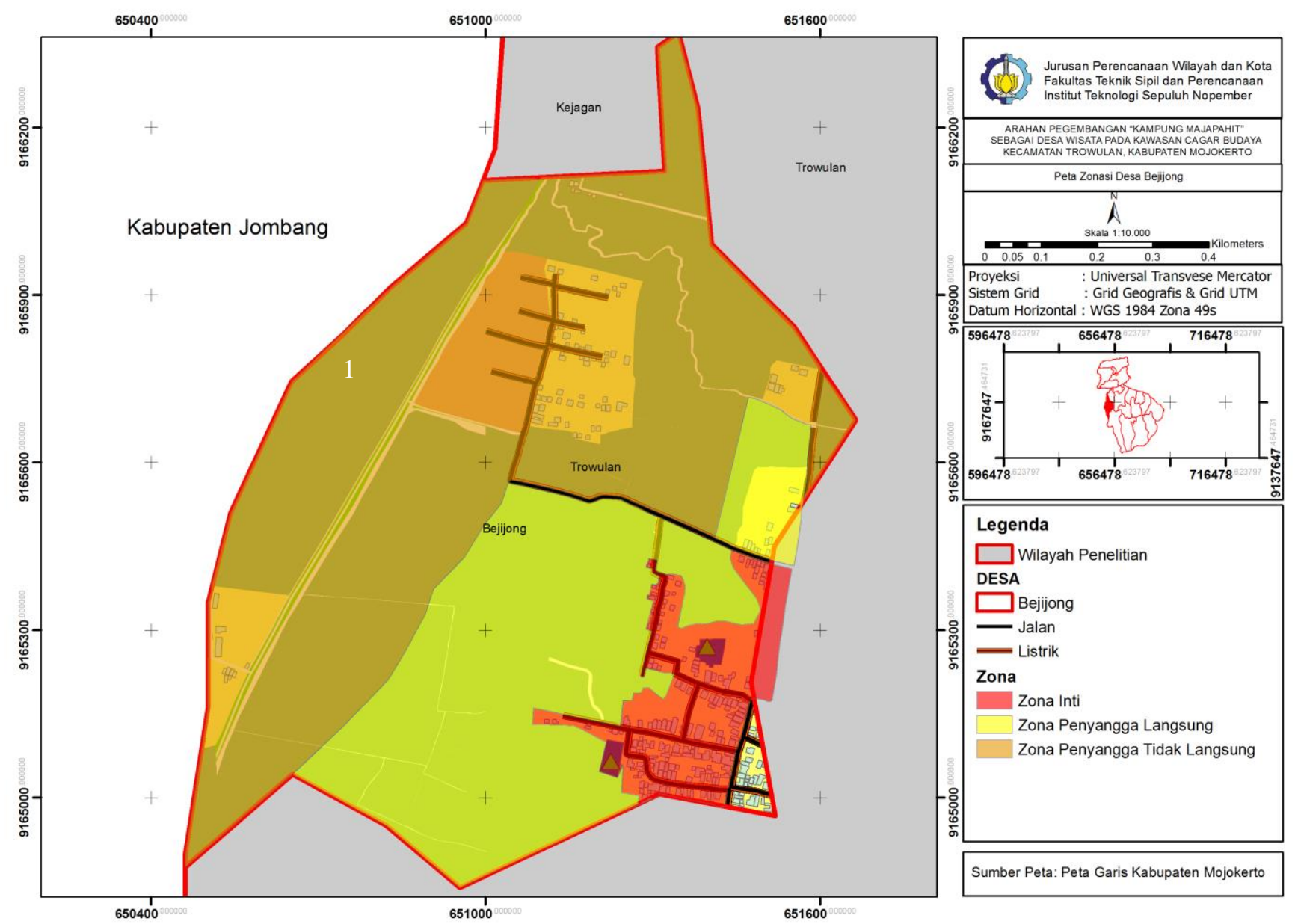

Gambar 1 Contoh pembagian zonasi pengembangan pariwisata Kampung Majapahit

Untuk arahan mikro per zona pengembangan yang dihasilkan adalah sebagai berikut:

1. Zona Inti dengan arahan mikro berupa:1) Peningkatan kualitas bangunan cagar budaya atau situs candi pada area sekitar Kampung Majapahit; 2) Peningkatan kualitas budaya lokal demi peningkatan daya tarik wisata; 3) Pengadaan kegiatan eventual dalam melestarikan budaya lokal; 4) Penempatan sanggar dan sarana pementasan pada zona inti pengembangan Desa Jatipasar; 5) Penempatan sanggar dan sarana pementasan pada zona inti pengembangan Desa Jatipasar; 6) Penambahan fasilitas pelayanan pariwisata pada kawasan inti information centre. Khusus information centre diarahkan pada kawasan inti pada Desa Bejijong; 7) Penambahan fasilitas pelayanan pariwisata pada kawasan inti yang berupa galeri seni yang dipusatkan pada Desa Bejijong; 8) Pemberian rute wisata di jalan-jalan lingkungan di Kampung Majapahit yang didukung dengan adanya moda transportasi budaya berupa becak dan dokar.

2. Zona Pendukung Langsung dengan berupa: 1) Menambah maupun melakukan perbaikan fasilitas wisata pada Kampung Majapahit demi menunjang pariwasata situs Majapahit; 2) Pemberian ruang parkir kendaraan wisata seperti dokar, becak; 3) Peningkatan kualitas museum Majapahit; 4) Penambahan fasilitas pendukung pariwisata
Kampung Majapahit berupa penambahan puskesmas pada zona pendukung pada Desa Bejijong.

3. Zona Pendukung Tidak Langsung dengan berupa: 1) Memberikan information board di depan bangunan tersebut mengenai sejarah bangunan; 2) Peningkatan kualitas museum dari segi fisik dengan memberikan guidelines tentang cara-cara perbaikan, renovasi, dan pemugaran bangunan agar tidak terjadi tindakan yang bersifat merusak. Guidelines tersebut dapat dilakukan perbaikan dan pemugaran sesuai dengan kebutuhan bangunan tersebut dengan memperhatikan peraturan yang sudah ada; 3) Pemberian ruang untuk parkir terpusat untuk sarana pendukung pariwisata Kampung Majapahit

\section{Integrasi Wisata Kampung Majapahit dengan Situs} Majapahit

Kampung Majapahit pada dasarnya merupakan bagian kampung yang tidak berbatasan langsung antar kampung. Korelasi antar Kampung Majapahit dengan situs-situs yang terangkai dalam lingkungan sekitar merupakan potensi untuk dirangkai guna memperkuat peran situs sebagai landmark kawasan dan memperkuat aura sekitar situs agar tetap tampak magis, natural, ataupun artistik, lingkungan sekitar situs ini dapat berupa aset budaya alam, maupun aset budaya ragawi lingkungan permukiman pedesaan, lingkungan permukiman/home industy kerajinan rakyat (kuningan, patung batu, dll), Kampung Majapahit yang berkesan "urban - village" 
atau aset budaya ragawi lain (warung-warung wader, kesenian ludruk, tari, dll). Dalam integrasi Kampung Majapahit dapat dijabarkan menjadi berikut :

1. Desa Bejijong merupakan pusat dari pengembangan desa Wisata Majapahit. Hal ini dikarenakan Desa Bejijong merupakan perkampungan dan kolektifitas situs yang padat. Sehingga dalam pengintegrasian Kampung Majapahit Desa Bejijong menjadi pusat utama dalam fungsi kegiatan wisata budaya.

2. Sarana dan prasarana seperti parkir wisata dan kendaraan tematik wisata diarahkan pada zona pendukung langsung di Desa Jatipasar. Hal ini dikarenakan letak Desa Jatipasar yang memiliki akses langsung terhadap jalan raya provisi Surabaya - Jogja.

3. Pusat informasi (information centre) terkait Kampung
Majapahit dipusatkan pada Desa Bejijong yang dalam hal ini direncanakan sebagai pusat pengembangan dan informasi terkait Kampung Majapahit.

4. Sarana outlet dan pusat oleh oleh diarahkan pada Kampung Majapahit Jatipasar. Hal ini dikarenakan akses keluar pengunjung diarahkan menuju Desa Jatipasar

5. Sarana Museum dipusatkan pada Desa Sentonorejo. Selain letak museum yang berada di Desa Sentonorejo, situs di tersebeut juga cukup banyak. Sehingga dapat dijadikan alur wisata dari Desa Bejijong.

6. Pusat panggung pagelaran seni dipusatkan pada Desa Sentonorejo. Pada dasarnya permukiman pada Desa Sentonorejo tidak terlalu padat sehingga dalam pengembangan panggung pagelaran seni dapat di arahkan di Desa Sentonorejo

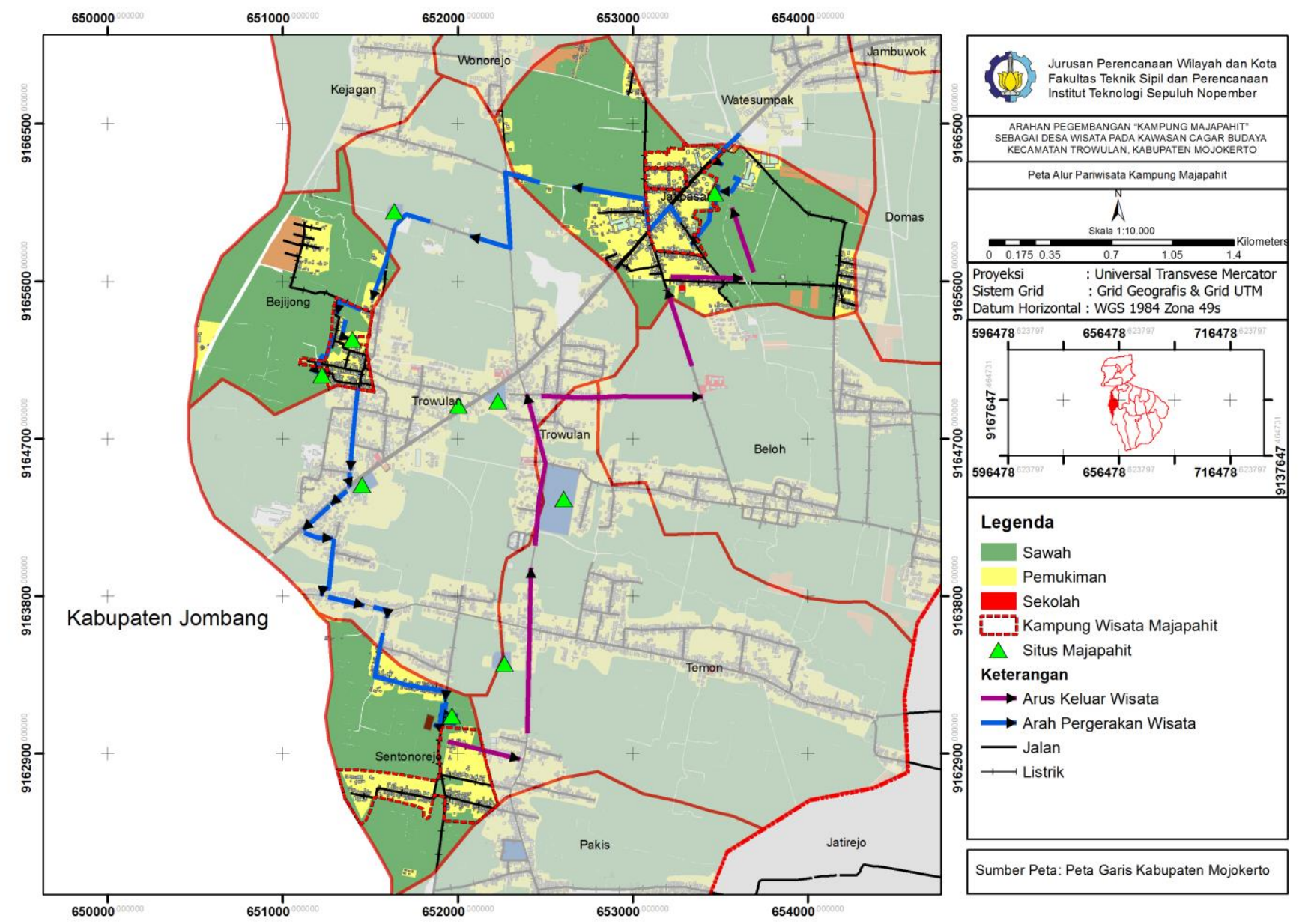

Gambar 2 Peta alur wisata Kampung Majapahit

\section{KESIMPULAN}

Dari proses analisa yang telah dilakukan, dapat disimpulkan bahwa Kawasan Kampung Majapahit layak untuk dikembangkan lebih menjadi kawasan wisata budaya dengan potensi di kawasan tersebut. Adapun pada arahan pengembangan kawasan Kampung Majapahit sebagai berikut:

1. Wisata budaya Kampung Majapahit dibagi menjadi 2 arahan, yakni arahan makro dan mikro. Arahan pengembangan kawasan sebagai wisata budaya secara mikro adalah arahan khusus pada setiap desa yang terdeliniasi. Sementara arahan makro merupakan arahan umum untuk kawasan deliniasi Kampung Majapahit

2. Dalam arahan per zona pengembangan kegiatan wisata secara konseptual dibagi menjadi 3 zona, antara lain zona inti, zona pendukung langsung, dan zona pendukung tidak langsung. Dimana dalam perumusan arahan mikro yang dihasilkan disesuaikan pula dengan karakteristik yang ada pada tiap zona pengembangan kegiatan wisata. 
3. Dalam pengintegrasian Kampung Majapahit berupa: 1) Desa Bejijong merupakan pusat dari pengembangan desa Wisata Majapahit; 2) Sarana dan prasarana seperti parkir wisata dan kendaraan tematik wisata diarahkan pada zona pendukung langsung di desa Jatipasar; 3) Pusat informasi (information centre) terkait Kampung Majapahit dipusatkan pada Desa Bejijong; 4) Sarana outlet dan pusat oleh-oleh diarahkan pada Kampung Majapahit Jatipasar; 5) Sarana Museum dipusatkan pada Desa Sentonorejo; 6) Pusat panggung pagelaran seni dipusatkan pada Desa Sentonorejo; 7) Penambahan jaringan jalan pada kawasan yang terkena dampak pariwisata.

Arahan pengembangan ini disesuaikan dengan kondisi existing sehingga dalam penarikan arahan dapat menyesuaikan kondisi nyata di lapangan.

\section{DAFTAR PUSTAKA}

[1] Hovinen, Gary R. (1995). Heritage Issues in Urban Tourism: An Assessment of New Trends in Lancaster County. Tourism Management 16(5): 381-388.

[2] Ariastita, T. A. (2014). Arahan Pengembangan Kota Palembang Sebagai Kota Pusaka . JURNAL TEKNIK POMITS Vol. 3, No.2,, 212-217.

[3] Ardika, I Wayan. (2003). Pariwisata Budaya Berkelanjutan, Refleksi dan Harapan di Tengah Perkembangan Global. Tesis. Programpascasarjana Universitas Udayana Bali.

[4] Ike Permatasari, A. W. (2008). PERMUKIMAN PERDESAAN DI DESA TROWULAN KECAMATAN TROWULAN KABUPATEN MOJOKERTO. arsitektur e- Journal, 78-93.

[5] Inskeep, Edward. (1991). Tourism Planning: An Integrated and Sustainable Development Approach. New York: John Wiley \& Sons IncImam Asy'ari, Sapari. 1993. Sosiologi Kota dan Desa. Surabaya : Usaha Nasional Surabaya

[6] Putu Agus Wiryawan Giri, T. W. (2012). PELESTARIAN POLA TATA RUANG TRADISIONAL DESA ADAT (PAKRAMAN) KALIBUKBUK DI KAWASAN PARIWISATA LOVINA KABUPATEN BULELENG, BALI . Jurnal Ilmiah, 1-17..

[7] Suprihardjo, F. Z. (2014). Konsep Pengembangan Kawasan Desa Wisata di Desa Bandungan Kecamatan Pakong Kabupaten Pamekasan . JURNAL TEKNIK POMITS Vol. 3, No.2, , 245-249. 